\title{
Breaking supercontinents; no need to choose between passive or active
}

\author{
Martin Wolstencroft ${ }^{1,2}$ and J. Huw Davies ${ }^{2}$ \\ ${ }^{1}$ JBA Risk Management, Skipton, BD23 3AE, England, UK \\ ${ }^{2}$ School of Earth and Ocean Sciences, Cardiff University, CF10 3 YE, Wales, UK \\ Correspondence to: J. Huw Davies (daviesjh2@cardiff.ac.uk)
}

Received: 5 February 2017 - Discussion started: 8 February 2017

Revised: 29 May 2017 - Accepted: 5 June 2017 - Published: 7 August 2017

\begin{abstract}
Much debate has centred on whether continental break-up is predominantly caused by active upwelling in the mantle (e.g. plumes) or by long-range extensional stresses in the lithosphere. We propose the hypothesis that global supercontinent break-up events should always involve both. The fundamental principle involved is the conservation of mass within the spherical shell of the mantle, which requires a return flow for any major upwelling beneath a supercontinent. This shallow horizontal return flow away from the locus of upwelling produces extensional stress. We demonstrate this principle with numerical models, which simultaneously exhibit both upwellings and significant lateral flow in the upper mantle. For non-global break-up the impact of the finite geometry of the mantle will be less pronounced, weakening this process. This observation should motivate future studies of continental break-up to explicitly consider the global perspective, even when observations or models are of regional extent.
\end{abstract}

\section{Introduction}

Continental break-up leading to new ocean basins has been a fundamental component of the plate tectonic system since at least the late Proterozoic. The geologic record provides evidence that continents are assembled into larger supercontinents and subsequently broken apart in a cyclical manner (e.g. Wilson, 1966; Bleeker, 2003; Rogers and Santosh, 2003; Bradley, 2011). The source of the force that "breaks" a continent is of particular interest and continues to be actively studied (Gao et al., 2013; Buiter and Torsvik, 2014; Koptev et al., 2015).
This paper does not attempt to explain the whole history and mechanics of plate tectonic history, nor does it consider the fine detail of crustal fracture processes. Instead, we consider the solid Earth system of lithosphere and mantle as a dynamic whole and present the implications of this viewpoint for the large-scale mechanics of continental break-up. Our discussion is mediated by the use of realistic scale and geometry numerical models of mantle circulation.

\section{Previous work}

Long-range plate-mediated extensional tectonic forces (White and McKenzie, 1989) and uplift forces produced by thermally or chemically buoyant mantle (Hooper, 1990; Storey et al., 1995) have both been proposed as candidate mechanisms to drive continental break-up. In the literature, these two mechanisms developed into end-member hypotheses: a "passive" model, which relies on extensional stresses, and an "active" mechanism, which involves a thermally buoyant feature underneath a continent. The latter is also known as the "plume model". The passive/active terminology originated with Şengör and Burke (1978) and was widely used or implied in the subsequent literature (e.g. Turcotte and Emerman, 1983; Bott, 1992, 1995; Huismans et al., 2001; Allen and Allen, 2005).

Evidence, which might discriminate between the proposed break-up mechanisms, is equivocal as lithospheric extension and plume-head-like activity seem to be related in a complex manner. White and McKenzie (1989) favour extension as the main driver of break-up, proposing that the volcanism associated with continental break-up (e.g. Central Atlantic Magmatic Province) is related to higher mantle temperatures, 
which develop under large continents through insulation (e.g. Gurnis, 1988; Brandl et al., 2013), although this is not universally accepted (e.g. Heron and Lowman, 2014). Experimental results have demonstrated how lithospheric thinning and dyke-like volcanism could be linked to thermochemical instability of the lower lithosphere in moderately old cratons (Fourel et al., 2013). Continental break-up appears to occur preferentially on alignments of previous continental collision, suggesting that strain localizes at lithospheric weak points (Corti et al., 2007), favouring the passive model. However, in a classic modelling study, Bott (1992) concluded that simply passive upwelling of mantle in response to local lithospheric thinning cannot initiate break-up; a more significant source of stress - such as a plume - is required.

The presence of volcanism has been used to argue that mantle plumes actively cause break-up (Storey et al., 1995), although there are examples where plume magmatism has not resulted in break-up (Sobolev et al., 2011). Storey (1995) concluded that some regions of Gondwana underwent breakup with voluminous volcanism but other regions did so without. Ziegler and Cloetingh (2004) report large variations in the duration of break-up, from effectively instant break-up to many tens of millions of years of rifting prior to breakup. Cloetingh et al. (2013) suggest that plumes modify lithosphere strength and help initiate break-up in an extensional setting, producing the classic "plume head" effects. This evidence of combined extensional and plume activity argues for an active plus passive mode, with the simultaneous occurrence of a hot upwelling feature and continental-scale lithospheric extension. Bott $(1992,1995)$ speculated that such a combined process may be required to achieve full breakup, but how this might occur was left unresolved.

The assumption that drag forces exerted by mantle flow on the lithosphere are too small to influence plate motions (Forsyth and Uyeda, 1975) influenced subsequent debate. This assumption has been questioned by active-source seismic tomography studies (Kodaira et al., 2014), which indicate that mantle flow may influence plate motion. Sophisticated numerical modelling studies also suggest that largescale mantle flow may act as a "conveyor belt", with plate motions influenced by flow away from active upwelling (Becker and Faccenna, 2011; Cande and Stegman, 2011). Therefore, it seems possible that large-scale lateral flow in the upper mantle is capable of producing stress in the lithosphere in certain scenarios. It is interesting to consider whether certain dynamic mantle behaviours could set up such large-scale flow and thereby set up the necessary physical conditions for continental break-up to occur.

Long-timescale mantle convection is difficult to constrain empirically and extensive use has been made of numerical modelling. Previous studies of mantle convection in both 2-D Cartesian and spherical geometry have shown that Earth's mantle is or has been transitionally layered about the $660 \mathrm{~km}$ deep Olivine phase boundary (Davies, 1995; Yanagisawa et al., 2010; Wolstencroft and
Table 1. Common input values.

\begin{tabular}{ll}
\hline Parameter & Value \\
\hline Equation of state & Incompressible Boussinesq \\
Reference density & $4500 \mathrm{~kg} \mathrm{~m}^{-3}$ \\
Density change across $660 \mathrm{~km}$ & $9.1 \%$ \\
Gravitational acceleration & $10 \mathrm{~m} \mathrm{~s}^{-2}$ \\
Vol. coefficient of thermal ex- & $2.5 \times 10^{-5} \mathrm{~K}^{-1}$ \\
pansion & \\
Thermal conductivity & $4 \mathrm{~W} \mathrm{~m}^{-1} \mathrm{~K}^{-1}$ \\
Specific heat (constant volume) & $1000 \mathrm{~J} \mathrm{~K}^{-1} \mathrm{~kg}^{-1}$ \\
Temperature at surface & $300 \mathrm{~K}^{*}$ \\
Temperature at CMB & $2850 \mathrm{~K}$ \\
Radioactive heating & $5 \times 10^{-12} \mathrm{~W} \mathrm{~kg}^{-1}$ \\
Velocity boundary conditions & Free slip \\
Inner radius of shell & $3.480 \times 10^{6} \mathrm{~m}$ \\
Outer radius of shell & $6.370 \times 10^{6} \mathrm{~m}$ \\
\hline
\end{tabular}

* Since the model is incompressible, the adiabatic temperature gradient would need to be added for comparison to Earth core-mantle boundary (CMB) temperature.

Davies, 2011; Herein et al., 2013). The transitionally layered state demonstrates time-dependent behaviour such as mantle avalanches (Tackley, 1993). Near-surface factors such as plate rheology have also been shown to influence the preferred large-scale pattern of convection (e.g. Yoshida, 2008; Rolf et al., 2014). This study does not attempt to simulate this; we do not impose surface or near-surface conditions to simulate plates. Although the sources of time-dependent behaviour in the real Earth may be different, in this paper, avalanches are used as an example of a global-scale kinematic event in the mantle.

\section{Modelling method}

Modelling was carried out using the TERRA spherical geometry mantle convection model (Baumgardner, 1985; Bunge et al., 1997; Oldham and Davies, 2004; Davies and Davies, 2009; Wolstencroft and Davies, 2011). The parameter values given in Table 1 were held constant between model cases, while Table 2 contains parameters which were varied. Radial and mean lateral model resolution was $22 \mathrm{~km}$ for Cases 1 and 2 and $44 \mathrm{~km}$ for Case 3; continental lithosphere was not explicitly modelled.

Cases were permitted to evolve to a state where there was no long-term trend in heat flux through the mantle. Mantle rheology comprised uniform, radially variable (after Bunge et al., 1997) and temperature-dependent viscosity. The phase transition in the olivine system from ringwoodite to bridgmanite and ferropericlase at $660 \mathrm{~km}$ (660) was modelled using the sheet mass anomaly approach (Tackley, 1993), where buoyancy forces are applied to approximate the resistive effect of the 660 phase change on mantle flow (Christensen and Yuen, 1985). The density increase associ- 
Table 2. Model cases. Cl660 is the Clapeyron slope at 660; $R a$ is Rayleigh number (Eq. 1). U/LMV is the upper-lower mantle viscosity contrast; $T \mathrm{~d} V$ indicates temperature-dependent viscosity.

\begin{tabular}{llllll}
\hline Case & Cl660 $\left(\mathrm{MPa} \mathrm{K}^{-1}\right)$ & Phase buoyancy parameter & Reference viscosity & $R a$ & Notes \\
\hline $1^{\mathrm{a}}$ & -8 & -0.221 & $1.15 \times 10^{22}$ & $6.76 \times 10^{6}$ & Isoviscous \\
$2^{\mathrm{b}}$ & -4 & -0.111 & $9.18 \times 10^{20}$ & $8.48 \times 10^{7}$ & Isoviscous \\
3 & -8 & -0.221 & $2.00 \times 10^{22}$ & $6.97 \times 10^{6}$ & $10 \times \mathrm{U} / \mathrm{LMV}, T \mathrm{~d} V$ \\
\hline
\end{tabular}

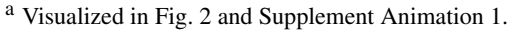

b Visualized in Fig. 3.

ated with the phase change at 660 is included (Table 1), and the phase buoyancy parameters (Wolstencroft and Davies, 2011, Eq. 6) are provided in Table 2. No other phase changes were modelled. The vigour of convection is expressed as the basally heated Rayleigh number $(R a)$.

$R a=\left(\alpha \rho g \Delta T D^{3}\right) / \kappa \eta$,

where $\alpha$ is the coefficient of thermal expansion, $\rho$ is average density of the two phases, $g$ is gravitational acceleration, $\Delta T$ is the temperature change across the mantle, $D$ is mantle thickness, $\eta$ is dynamic viscosity and $\kappa$ is thermal diffusivity $=k / \rho C_{p}$, where $k$ is thermal conductivity and $C_{p}$ is specific heat at constant pressure.

High $R a$ produces shorter wavelength convective features, which, by their weaker ability to counteract the negative buoyancy effect, are less able to break through the 660 phase change (Peltier, 1996), demonstrated by Tackley (1993). When running models at $R a$ lower than Earth-like $\left(\approx 10^{8}\right.$; Weeraratne and Manga, 1998) the modelled Clapeyron slope must be more negative to obtain Earth-like behaviour. The probable value of the real Clapeyron slope for 660 is $-2.5 \pm 0.4 \mathrm{MPaK}^{-1}$ (Ye et al., 2014).

\subsection{Depth-dependent viscosity}

Radial viscosity variations were set by a radially varying multiple of the reference viscosity (Table 2, after Bunge et al., 1997). The transition from upper to lower mantle occurs at $660 \mathrm{~km}$ depth. There is a stepped increase into the lower mantle across $660 \mathrm{~km}$, which is consistent with interpretations of Earth's real viscosity profile (Mitrovica and Forte, 2004).

\subsection{Temperature-dependent viscosity}

For the case with temperature dependence (Case 3), the assumed temperature dependence of viscosity is set by

$\eta(r \rightarrow, T)=\eta(r) e^{(4.6(0.5-T))}$,

where $T$ is the temperature normalized by the superadiabatic temperature change across the mantle, $\eta(r \rightarrow)$ the threedimensional viscosity field and $\eta(r)$ the radial viscosity profile. This relation allows viscosity variation up to a factor of

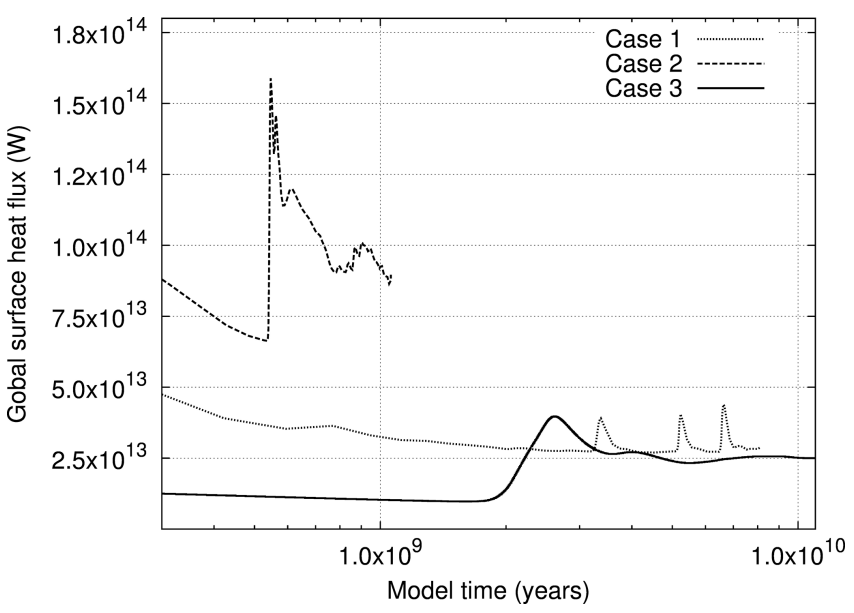

Figure 1. Model surface heat flux time series for the three cases presented, truncated to exclude variations as the model stabilizes the initial condition. The surface heat flux magnitude variations and timing offsets are the result of the varying vigour of convection.

100 , with a lower limit on the viscosity set to 2 orders of magnitude below the reference viscosity to ensure numerical stability of the model. For Case 3 the mean viscosity of the whole mantle is used to calculate the Rayleigh Number (Eq. 1).

\section{Modelling output}

We present three example model cases (Table 2). Cases 1 and 3 use a $R a$ that is $1-2$ orders of magnitude lower than Earth and $\mathrm{a} \approx 3 \times$ more negative 660 Clapeyron slope; Case 2 uses a near-Earth-like $R a$ and a 660 Clapeyron slope more negative than Earth. Using both scaled-down and near-Earthlike vigour gives us greater confidence that the dynamic processes modelled are plausible. Figure 1 demonstrates one defining feature of the transitional convective regime: periodic spikes in surface heat flux.

Figure 2 presents a detailed visualization of the first spike of Case 1. The event causing the spikes in surface heat flux proceeds as follows: cold material that has ponded in the upper mantle overcomes the resistance of 660 and avalanches into the lower mantle. The avalanche partially overturns the 

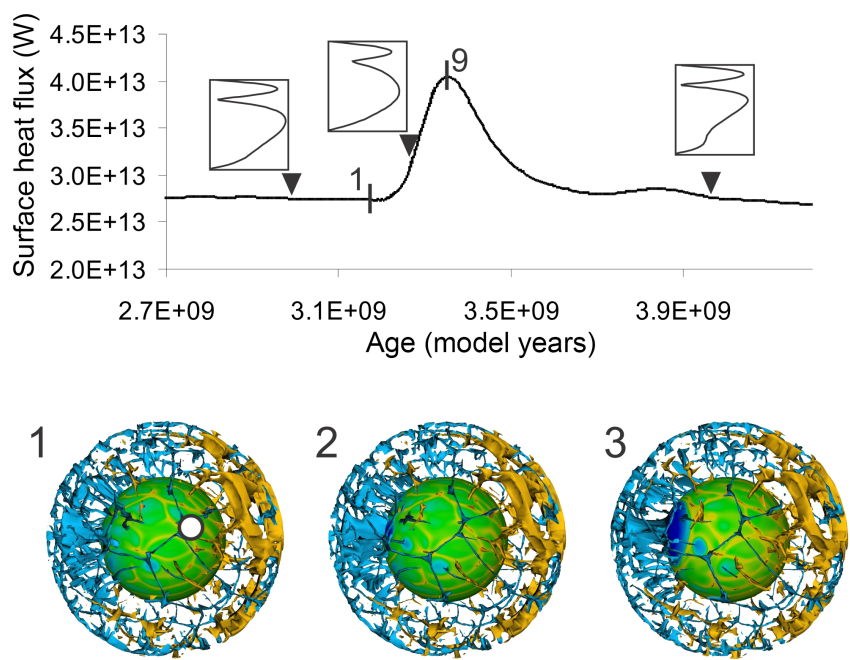

4
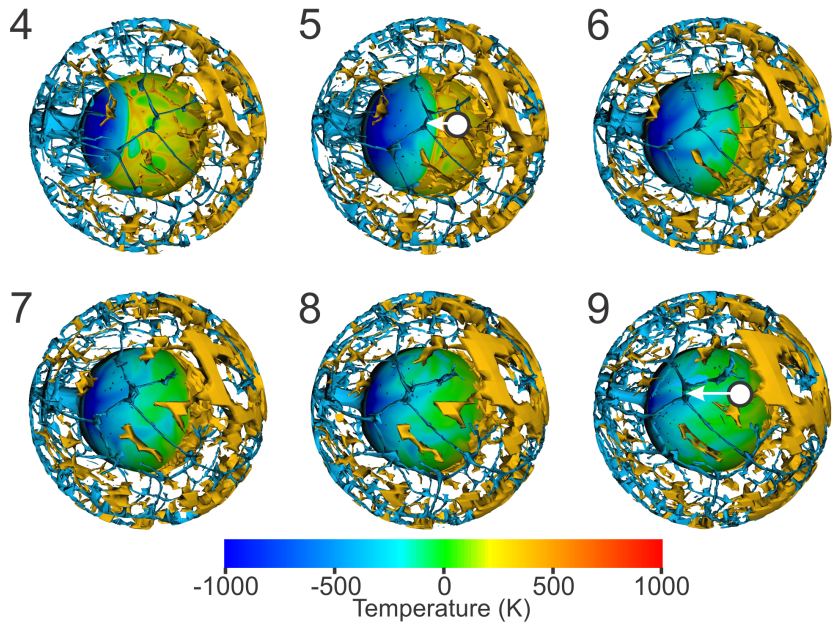

Figure 2. Visualization of Case 1, peak 1 shown in Fig. 1. In addition to surface heat flux, the graph provides three insets showing the absolute radial mass flux through the modelled mantle and the depth of the "pinch point" indicating how much 660 is restricting mass exchange between upper and lower mantle. Evenly spaced temperature anomaly snapshots (1-9) cover the indicated region of the surface heat flux curve. The white dot in 1,5 and 9 is fixed, and arrows show how the near surface material has moved. Temperature anomaly is plotted just above the CMB and as $\pm 400 \mathrm{~K}$ isosurfaces.

whole mantle, advecting a "pulse" of hot material into the upper mantle. This hot material cools rapidly - the surface heat flux spike. In terms of motion, this event produces globally organized surface-lateral flow towards the avalanche and radial flow above the antipodal upwelling. This motion is demonstrated in Supplement Animation 1.

Figure 3 demonstrates the same process at high $R a$ in Case 2 and demonstrates the universality of the global pattern. The global nature of these events is required by the inescapable conservation of mass; avalanches must have a return flow. Being rooted in fundamental physics of the finite

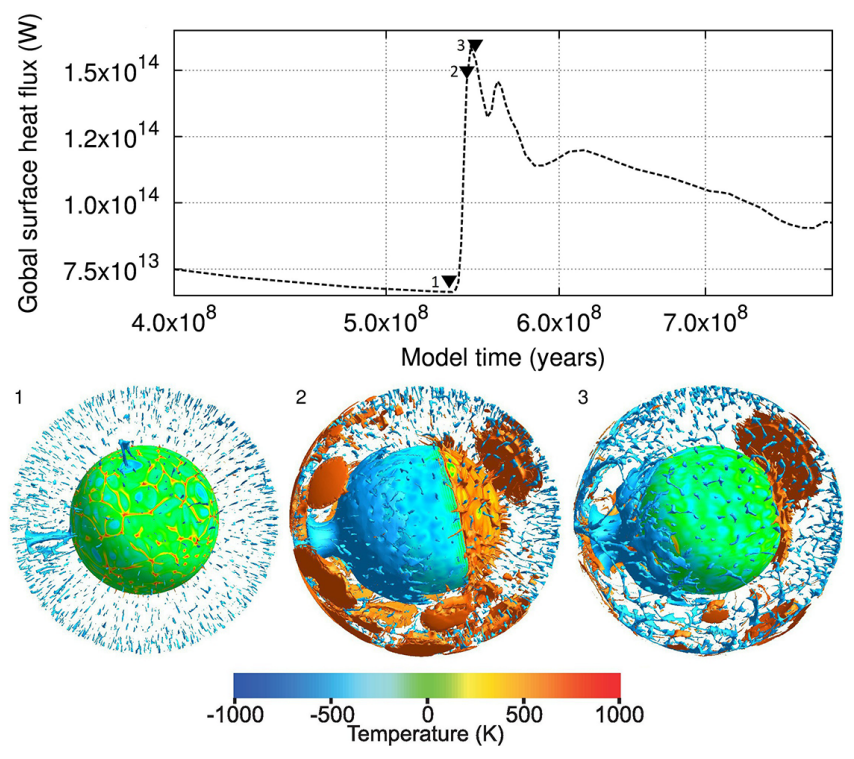

Figure 3. Visualization of Case 2. The graph (top) is an enlargement from Fig. 1; the numbered triangles indicate the time of the panels below. (1) The avalanche initiates; material from the upper mantle begins to enter the lower mantle where it shows up as anomalously cold. (2) Avalanche in full flow; antipodal plumes have already reached the surface. (3) The avalanche has now progressed to "pulling" hot material from the antipodal plume towards itself. Isosurfaces follow -500 and $+700 \mathrm{~K}$ anomalies; the uppermost $5 \%$ of the isosurfaces are clipped to improve clarity of the deep mantle.

mantle system, the effect of the return flow will apply universally, not just under the conditions of these illustrative cases.

Figure 4 demonstrates clearly how the surface velocity and temperature properties of the model change in response to the avalanche return flow in Case 2 . The velocity increase occurs slightly before the increase in surface heat flux, in accordance with the avalanche-then-plume sequence shown for this model (Fig. 3). An estimate of the real-Earth duration of these events was produced by taking the average (nonpulse) surface velocities and deriving a scaling factor vs. a real-Earth velocity of $5 \mathrm{~cm} \mathrm{yr}^{-1}$, by which event durations could be evaluated. For example, Case 2 with $\approx 3 \mathrm{~cm} \mathrm{yr}^{-1}$ velocity and the model event duration of $\approx 1 \times 10^{8} \mathrm{yr}$ produces a real-Earth duration of $\approx 60 \mathrm{Myr}$. We have used this approach previously to estimate durations between mantle avalanches (Wolstencroft, 2008).

\section{Discussion}

The debate between passive and active models of continental break-up probably represents a false dichotomy, as continental break-up seems to display or indeed require characteristics of both mechanisms (e.g. Bott, 1992; Storey, 1995). Our modelling provides an example of how this might occur, through dynamic events, which impact a large proportion of 


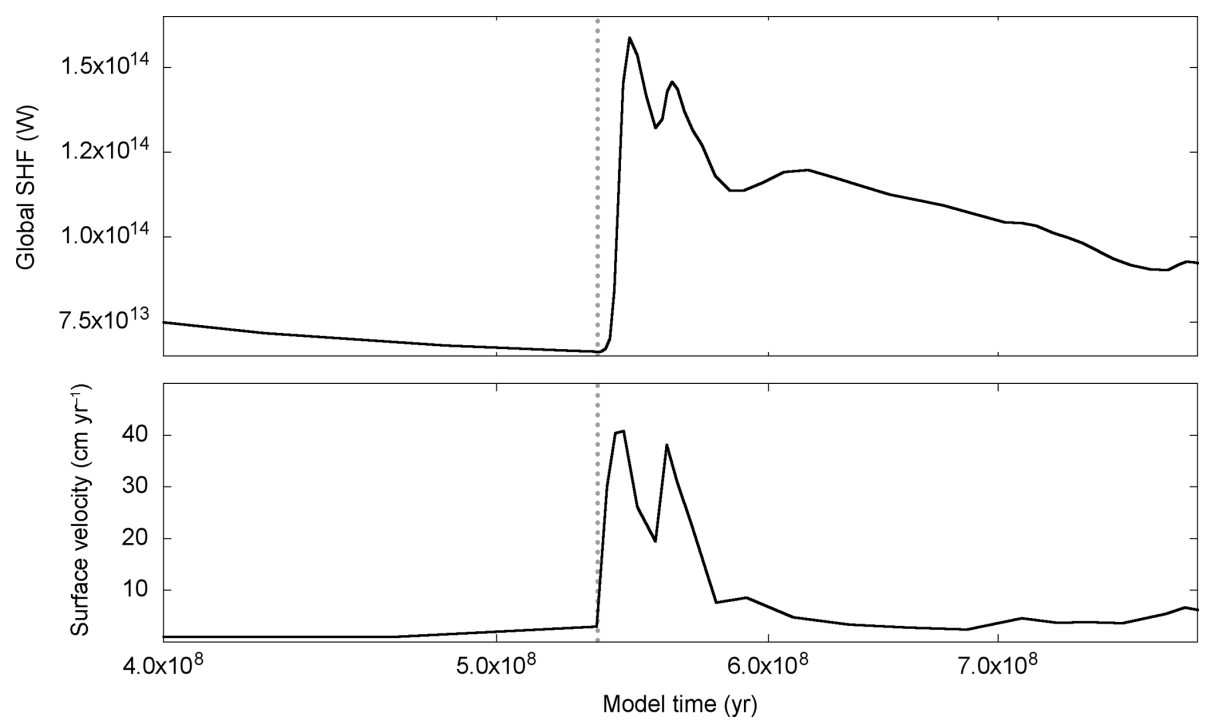

Figure 4. Plot of global surface heat flux and horizontal velocity for Case 2. Both curves are plotted with data points at the same time intervals; grey dotted line demonstrates the timing offset between velocity and heat flux increase.

Earth's mantle for a geologically significant time. The most important aspect of our conceptual model is the return flow required by the conservation of mass on a global scale. In the subsections below, we consider several aspects and implications related to this central idea.

\subsection{Force estimates}

The viscous lithosphere used in this study cannot address the details of rifting; accordingly, we only require the standard extension processes invoked in more detailed models (Huismans et al., 2001), i.e. far-field plate forces and upwelling generated forces to effect continental break-up. A first-order estimate of the driving force for extension arising from an active uplift is $<4 \times 10^{12} \mathrm{Nm}^{-1}$; a similar estimate of the driving force for extension from passive distant plate forces is $<3 \times 10^{12} \mathrm{Nm}^{-1}$ (subduction suction) or $<5 \times 10^{12} \mathrm{Nm}^{-1}$ (subduction slab pull) (Kusznir, 1991). Estimates of the strength of the lithosphere are sensitive to its temperature and crustal thickness and range from 2$20 \times 10^{12} \mathrm{Nm}^{-1}$ using simple strength envelope assumptions with constant velocity (Davies and von Blanckenburg, 1998) and $4-9 \times 10^{12} \mathrm{Nm}^{-1}$ for low strain rates (Stamps et al., 2010).

Comparing the values above, it is unsurprising that breakup might require both processes, since their combined forces $\left(<8 \times 10^{12} \mathrm{~N} \mathrm{~m}^{-1}\right)$ are more likely to exceed the integrated strength (average range: $6.5-9 \times 10^{12} \mathrm{Nm}^{-1}$ ), as argued by Bott (1992). Going beyond such simple estimates requires complex rheology (Burov, 2011), deformation history and damage (Bercovici and Long, 2014), and combined plume and far-field stresses in ultra-high resolution (Burov and
Gerya, 2014), details that go beyond the scope of this discussion.

\subsection{Timescales and observables}

Our modelling is consistent with previous studies of timedependent or cyclical behaviour of the mantle (Sutton, 1963; Davies, 1995), and many numerical models have demonstrated mantle avalanches (Machetel and Weber, 1991; Tackley, 1993; O’Neill et al., 2007; Herein et al., 2013). We have demonstrated that the behaviour is evident across a range of $R a$ for an isoviscous rheology and for a case with depth- and temperature-dependent viscosity. Further rheological variations are possible but are beyond the scope of this study. For example, Höink et al. (2012) describe how interactions between a high-viscosity lithosphere and a low-viscosity asthenosphere can lead to lithosphere stress amplification, a process, which could enhance the ability of mantle convection to promote break-up.

Analysis of the cycle of avalanche behaviour highlights the importance of the return flow (the pulse) to the surface (e.g. Condie, 1998). The avalanche-pulse mechanism has the potential to produce lithospheric stress through both large horizontal near-surface motion and temporally associated plumes. From the models presented, we estimate that the duration of such an event is of the order of tens of millions of years, a timescale comparable to the break-up of a continent and the opening of a new ocean.

During break-up under the conceptual model presented here, margin segments located near active upwellings would show evidence of extensive magmatism; margin segments along-strike, where upwelling is not as concentrated, would be dominated by extension. Thus, observations of both vol- 
canic and non-volcanic margins during break-up could be satisfied (e.g. Storey, 1995).

\subsection{Break-up mechanics}

It is clear that continental break-up can only be achieved if there is localization of deformation (Le Pourhiet et al., 2013; Moresi et al., 2007; Regenauer-Lieb et al., 2008). This is achieved by feedback and possibly the presence of magma (Corti et al., 2003). There is strong evidence that deformation localizes frequently on regions that have an inherited weakness since they were the sites of earlier continental break-up (Audet and Bürgmann, 2011; Buiter and Torsvik, 2014). While the simple estimates above considered the driving force that an upwelling can provide, hot upwellings can also lead to magmatism, which can help to weaken the lithosphere, e.g. by dyking (Bialas et al., 2010; Brune et al., 2013). The greater thickness of continental vs. ocean lithosphere may also act to magnify stresses through increased shear tractions between asthenosphere and lithosphere (e.g. Conrad and Lithgow Bertelloni, 2006, and references therein). We note that full spherical models incorporating more detailed lithospheric rheologies are only just starting to appear (Van Heck and Tackley, 2008; Rolf et al., 2012, 2014; Yoshida and Santosh, 2014), and it is only through further advances in such models that a more quantitative assessment of this hypothesis will be achieved.

The fundamental kinematics of the global situation that we demonstrate can also be seen in the modelling of Zhong et al. (2007), who associated supercontinent cycles with a low spherical-harmonic-degree convective structure. However, our schematic of the specific degree-1 scenario (Fig. 5a) appears to be different to the degree- 2 break-up scenario proposed by Zhong et al. (2007) (Fig. 5b). It is likely that this difference is a matter of interpretation of mantle-lithosphere interaction, since plate-driven extension could be generated by slab suction from fringing subduction (Lowman and Jarvis, 1996; Bercovici and Long, 2014), as well as from distant plate motions. Indeed, given that we do not model a supercontinent over our upwelling, it is a reasonable expectation that such a continent would not stay static but would tend to migrate towards the downwellings even as it breaks up, leading to a more degree- 2 mode of convection in the manner of Zhong et al. (2007). It is likely that the pattern of mantle convection has evolved over time and that other factors will influence the detail (e.g. Faccenna and Dal Zilio, 2017). The critical point that will hold is that the surface convergence must be away from the surface supercontinent and that the upwelling will impact the supercontinent; platedriven extension represents a common component and our principle of mass conservation would still apply.

Aside from mantle avalanches - used as an example mechanism here - subduction reorganization offers another possible mechanism to produce global-scale flow to cause supercontinent break-up. Goes et al. (2008) demonstrated how
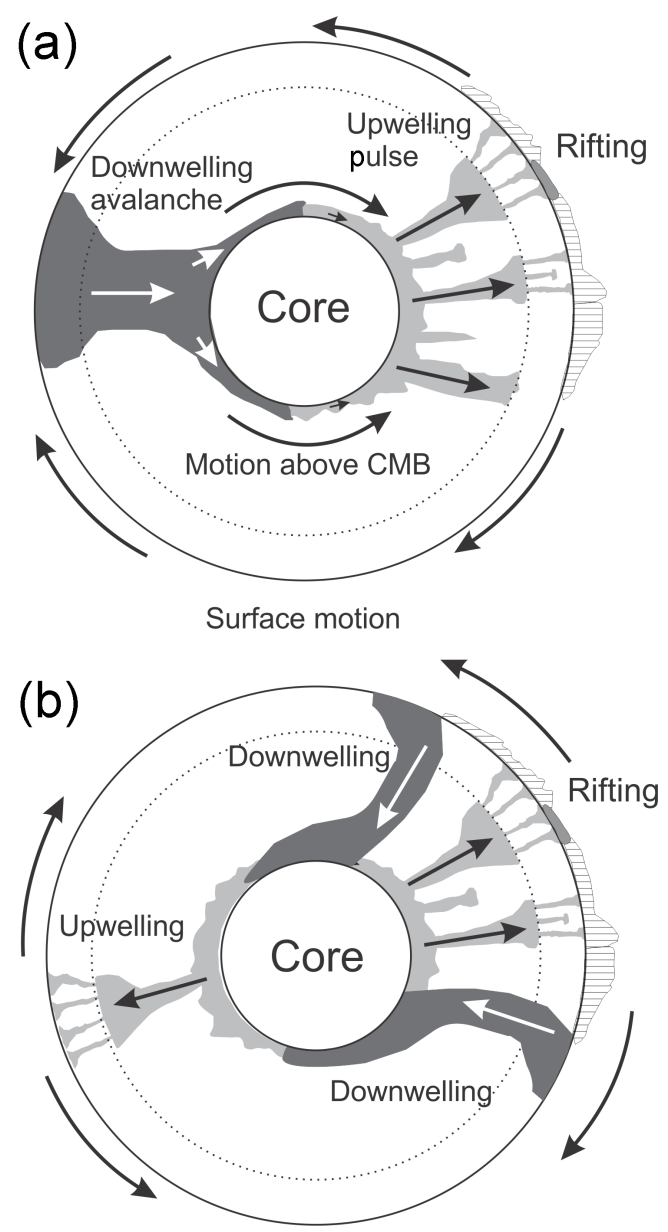

Figure 5. Conceptual sketch of the proposed mechanism of breakup. (a) Interpretation from Cases 1 and 2. (b) A further possible configuration of large-scale return flow involving continent fringing subduction zones (after Zhong et al., 2007). Not to scale.

slabs could "pile up" or "lay down" above 660, causing subduction to be constrained within the upper mantle and to slow down, potentially leading to stresses sufficient to build mountain chains (Faccenna et al., 2017). When slabs do sink into the lower mantle, the length scale of subduction can increase. If sufficient material is involved, a lateral flow regime similar to that produced by a mantle avalanche mechanism is set up - producing sufficient stress over durations that could lead to supercontinent break-up (Dal Zilio et al., 2017).

\subsection{Modelling limitations}

As the models presented are an illustrative selection, there are aspects of the solid Earth system which they either do not capture or capture in a simplified manner. In terms of direct geodynamic relevance, given that all models are inaccurate in some way, we chose to limit our models to avoid the danger of over-interpretation that can occur where models are considered more "real", e.g. incorporating complex 
chemical heterogeneity. This leads to some oddities; for example, Case 2 demonstrates a rather high surface heat flux (Fig. 3), but this is a natural consequence of not imposing a high-viscosity - or even rigid - simulated lithosphere (Sect. 2). Thus, the absolute value of surface heat flux from our models is not comparable to the Earth. The lack of a simulated lithosphere also means we do not draw conclusions on detailed break-up mechanics in the lithosphere. Our most complex model - Case 3 - implements a layered radial viscosity profile and allows temperature-dependent viscosity. These viscosity features were introduced together, as they are somewhat complimentary in the transitionally layered state a temporarily isolated lower mantle heats up and becomes less viscous.

\section{Summary}

We do not claim that the avalanche-pulse mechanism discussed above is essential for continental break-up; episodic tectonics could have a range of sources (e.g. O'Neill et al., 2007). Even without the avalanche mechanism, we speculate that the return flow required by mass conservation as plumes rise may lead to extensional stresses in the lithosphere. In reality we might expect a more complex situation, with multiple length scales of convection existing on differing timescales (e.g. compare Cases 1-3). The effectiveness of the mechanism may also depend on continent size. The role of global-scale conservation of mass in organizing subplate horizontal mantle flow between upwellings and downwellings is significant because of the hemispheric scale of supercontinents. If the continents being considered are smaller, the impact would be weaker and more subject to variability in the location of upwellings and downwellings. For the breakup of the smallest continental fragments, the geometry of the flow-conserving mass might not be reinforcing in terms of horizontal stress; on this basis small continents should frequently be more difficult to break.

Considering continental break-up as a global-scale geodynamic event involving both mantle and crust has clear advantages. This dynamic behaviour is capable of

- exerting extensional stresses over long timescales over large areas

- delivering plume-like features from below in a more spatially discontinuous manner.

This variable temporal and spatial relationship between extensional stressing and plume arrival could produce the observed variation in apparent rifting mode. As the process described is most applicable to large-scale continent break-up, if a supercontinent is successfully broken-up, we would expect both passive and active drivers to be identifiable. Continental break-up modelling is an active field (e.g. Allken et al., 2011; Gueydan and Précigout, 2014); however, integrating regional lithospheric and global convection models is a significant challenge. We suggest that future modelling studies should strive to include realistic-scale return flows to place continental break-up in the correct global context.

Data availability. The raw outputs of the models used to illustrate the points made in this paper are not available due to their very large data volume and limited scope for re-use. The information needed to reproduce our model runs in another mantle modelling framework is encompassed within the paper and further information can be obtained by contacting the authors.

\section{The Supplement related to this article is available online at https://doi.org/10.5194/se-8-817-2017-supplement.}

Author contributions. Both authors contributed equally to the manuscript.

Competing interests. The authors declare that they have no conflict of interest.

Acknowledgements. The authors would like to thank D. Rhodri Davies, Ian T. Jardine, Glenn Milne, Peter Webb, David Oldham, and Peter Bollada. Modelling was carried out on HECToR, the UK National Supercomputer, and Merlin at Cardiff University. Part of the work was supported by NERC: NER/S/A/2005/13131.

Edited by: Gwenn Peron-Pinvidic

Reviewed by: two anonymous referees

\section{References}

Allen, P. A. and Allen, J. R.: Basin Analysis, Principles and Applications, 2nd edn., Blackwell Publishing, Oxford, UK, ISBN: 0632052074,549 pp., 2005.

Allken, V., Huismans, R. S., and Thieulot, C.: Threedimensional numerical modeling of upper crustal extensional systems, J. Geophys. Res., 116, B10409, https://doi.org/10.1029/2011JB008319. 2011.

Audet, P. and Bürgmann, R.: Dominant role of tectonics inheritance in supercontinent cycles, Nat. Geosci., 4, 184-187, 2011.

Baumgardner, J. R.: Three dimensional treatment of convective flow in the Earth's mantle, J. Stat. Phys., 39, 501-511, 1985.

Becker, T. W. and Faccenna, C.: Mantle conveyor beneath the Tethyan collisional belt, Earth Planet. Sc. Lett., 3103, 453-461, 2011.

Bercovici, D. and Long, M. D.: Slab rollback instability and supercontinent dispersal, Geophys. Res. Lett., 41, 6659-6666, 2014.

Bercovici, D. and Ricard, Y.: Plate tectonics, damage and inheritance, Nature, 508, 513-516, 2014. 
Bialas, R., Buck, W. R., and Qin, R.: How much magma is required to rift a continent?, Earth Planet. Sc. Lett., 292, 68-78, 2010.

Bleeker, W.: The late Archean record: a puzzle in ca. 35 pieces, Lithos, 71, 99-134, 2003.

Bott, M. H. P.: The stress regime associated with continental breakup, in: "Magmatism and the Causes of Continental Break-up", edited by: Storey, B. C., Alabaster, T., and Pankhurst, R., J., Geol. Soc. Lond. Spec. Pub. 68, 125-136, 1992.

Bott, M. H. P.: Mechanisms of rifting: geodynamic modeling of continental rift systems, in: Continental Rifts: Evolution, Structure, Tectonics, Developments in Geotectonics, edited by: Olsen, K. H., 25, 27-43. Elsevier, Amsterdam, ISBN: 0444 89567 1, 466 pp., 1995.

Bradley, D. C.: Secular trends in the geologic record and the supercontinent cycle, Earth-Sci. Rev., 108, 16-33, 2011.

Brandl, P. A., Regelous, M., Beier, C., and Haase, K. M.: High mantle temperatures following rifting caused by continental insulation, Nat. Geosci., 6, 391-394, 2013.

Brune, S., Popov, A. A., and Sobolev, S. V.: Quantifying the thermomechanical impact of plume arrival on continental break-up, Tectonophysics, 604, 51-59, 2013.

Buiter, S. J., and Torsvik, T. H.: A review of Wilson Cycle plate margins: a role for mantle plumes in continental break-up along sutures?, Gondwana Res., 26, 627-653, 2014.

Bunge, H. P., Richards, M. A., and Baumgardner, J. R.: A sensitivity study of three-dimensional spherical mantle convection at $10^{8}$ Rayleigh number: effects of depth dependent viscosity, heating mode, and an endothermic phase change, J. Geophys. Res.-Sol. Ea., 102, 11991-12007, 1997.

Burov, E. B.: Rheology and strength of the lithosphere, Mar. Petrol. Geol., 28, 1402-1443, 2011.

Burov, E. and Gerya, T.: Asymmetric three-dimensional topography over mantle plumes, Nature, 513, 85-89, 2014.

Cande, S. C. and Stegman, D. R.: Indian and African plate motions driven by the push force of the Reunion plume head, Nature, 4757354, 47-52, 2011.

Christensen, U. R. and Yuen, D. A.: Layered convection induced by phase transitions, J. Geophys. Res., 90, 10291-10300, 1985.

Cloetingh, S., Burov, E., and Francois, T.: Thermo-mechanical controls on intra-plate deformation and the role of plume-folding interactions in continental topography, Gondwana Res., 24, 815837,2013

Condie, K. C.: Episodic continental growth and supercontinents: a mantle avalanche connection?, Earth Planet. Sc. Lett., 163, 97108, 1998.

Conrad, C. P. and Lithgow Bertelloni, C.: Influence of continental roots and asthenosphere on plate mantle coupling, Geophys. Res. Lett., 33, L05312, https://doi.org/10.1029/2005GL025621, 2006.

Corti, G., Bonini, M., Conticelli, S., Innocenti, F., Manetti, P., and Sokoutis, D.: Analogue modelling of continental extension: a review focused on the relations between the patterns of deformation and the presence of magma, Earth-Sci. Rev., 63, 169-247, 2003.

Corti, G., van Wijk, J., Cloetingh, S., and Morley, C. K.: Tectonic inheritance and continental rift architecture: numerical and analogue models of the East African Rift system, Tectonics, 26, TC6006, 2007.
Dal Zilio, L., Faccenda, M., and Capitanio, F.: The role of deep subduction in supercontinent breakup, Tectonophysics, https://doi.org/10.1016/j.tecto.2017.03.006, in press, 2017.

Davies, D. R. and Davies, J. H.: Thermally-driven mantle plumes reconcile multiple hot-spot observations, Earth Planet. Sc. Lett., 278, 50-54, 2009.

Davies, G. F.: Punctuated tectonic evolution of the Earth, Earth Planet. Sc. Lett., 136, 363-379, 1995.

Davies, J. H. and von Blanckenburg, F.: Thermal controls on slab breakoff and the rise of high-pressure rocks during continental collisions, in: When Continents Collide: Geodynamics and geochemistry of Ultrahigh-Pressure Rocks, edited by: Hacker, B. R. and Liou, J. G., Kluwer Academic Publishers, Dordrecht, the Netherlands, 97-115, ISBN-10: 0412824205, ISBN-13: 9780412824203, 1998.

Faccenna, C., Oncken, O., Holt, A. F., and Becker, T. W.: Initiation of the Andean orogeny by lower mantle subduction, Earth Planet. Sci. Lett., 463, 189-201, 2017.

Faccenna, M. and Dal Zilio, L.: The role of solid-solid phase transitions in mantle convection, Lithos, 268, 198-224, 2017.

Forsyth, D. and Uyeda, S.: On the relative importance of the driving forces of plate motion, Geophys, J. Roy. Astr. S., 43, 163-200, 1975.

Fourel, L., Milelli, L., Jaupart, C., and Limare, A.: Generation of continental rifts, basins, and swells by lithosphere instabilities, J. Geophys. Res.-Sol. Ea., 118, 1-21, 2013.

Gao, S. S., Liu, K. H., Reed, C. A., Massinque, B., Mdala, H., Moidaki, M., Mutamina, D., Atekwana, E. A., Shane Ingate, S., and Reusch, A. M.: Seismic arrays to study african rift initiation, EOS T. Am. Geophys. Un., 94, 213-214, 2013.

Goes, S., Capitanio, F. A., and Morra, G.: Evidence of lower-mantle slab penetration phases in plate motions, Nature, 451, 981-984, 2008.

Gueydan, F. and Précigout, J.: Modes of continental rifting as a function of ductile strain localization in the lithospheric mantle, Tectonophysics, 612-613, 18-25, 2014.

Gurnis, M.: Large-scale mantle convection and the aggregation and dispersal of supercontinents, Nature, 332, 695-699, 1988.

Herein, M., Galsa, A., and Lenkey, L.: Impact of the Rayleigh number and endothermic phase transition on the time behaviour of mantle avalanches, J. Geodyn., 66, 103-113, 2013.

Heron, P. J. and Lowman, J. P.: The impact of Rayleigh number on assessing the significance of supercontinent insulation, J. Geophys. Res.-Sol. Ea., 119, 711-733, 2014.

Höink, T., Lenardic, A., and Richards, M.: Depth-dependent viscosity and mantle stress amplification: implications for the role of the asthenosphere in maintaining plate tectonics, Geophys. J. Int., 191, 30-41, 2012.

Hooper, P., R.: The timing of crustal extension and the eruption of continental flood basalts, Nature, 345, 246-249, 1990.

Huismans, R. S., Podladchikov, Y. Y., and Cloetingh, S.: Transition from passive to active rifting: relative importance of asthenospheric doming and passive extension of the lithosphere, J. Geophys. Res., 106, 11271-11291, 2001.

Kodaira, S., Fujie, G., Yamashita, M., Sato, T., Takahashi, T., and Takahashi, N.: Seismological evidence of mantle flow driving plate motions at a palaeo-spreading centre. Nat. Geosci., 7, 371375, 2014. 
Koptev, A., Calais, E., Burov, E., Leroy, S., and Gerya, T.: Dual continental rift systems generated by plume-lithosphere interaction, Nat. Geosci., 8, 388-392, 2015.

Kusznir, N. J.: The distribution of stress with depth in the lithosphere: thermo-rheological and geodynamics constraints, Philos. T. R. Soc. A, 337, 95-110, 1991.

Le Pourhiet, L., Huet, B., Labrousse, L., Yao, K., Agard, P., and Jolivet, L.: Strain localisation in mechanically layered rocks beneath detachment zones: insights from numerical modelling, Solid Earth, 4, 135-152, https://doi.org/10.5194/se-4-135-2013, 2013.

Lowman, J. P. and Jarvis, G. T.: Continental collisions in wide aspect ratio and high Rayleigh number two dimensional mantle convection models, J. Geophys. Res-Sol. Ea., 101, 25485-25497, 1996.

Machetel, P. and Weber, P.: Intermittent layered convection in a model mantle with an endothermic phase change at $670 \mathrm{~km}$, Nature, 350, 55-57, 1991.

Mitrovica, J. X. and Forte, A. M.: A new inference of mantle viscosity based upon joint inversion of convection and glacial isostatic adjustment data, Earth Planet. Sc. Lett., 225, 177-189, 2004.

Moresi, L., Quenette, S., Lemiale, V., Mériaux, C., Appelbe, B., and Mühlhaus, H.-B.: Computational approaches to studying nonlinear dynamics of the crust and mantle, Phys. Earth Planet. In., 163, 69-82, 2007.

Oldham, D. and Davies, J. H.: Numerical investigation of layered convection in a three-dimensional shell with application to planetary mantles, Geochem. Geophy. Geosy., 512, 1-25, 2004.

O’Neill, C., Lenardic, A., Moresi, L., Torsvik, T. H., and Lee, C. T.: Episodic Precambrian subduction, Earth Planet. Sc. Lett., 262, 552-562, 2007.

Peltier, W. R.: Phase-transition modulated mixing in the mantle of the Earth, Philos. T. Roy. Soc. A, 354, 1425-1447, 1996.

Regenauer-Lieb, K., Rosenbaum, G., and Weinberg, R. F.: Strain localisation and weakening of the lithosphere during extension, Tectonophysics, 458, 96-104, 2008

Rogers, J. J. W. and Santosh, M.: Supercontinents in Earth History, Gondwana Res., 6, 357-368, 2003.

Rolf, T., Coltice, N., and Tackley, P. J.: Linking continental drift, plate tectonics and the thermal state of the Earth's mantle, Earth Planet. Sc. Lett., 351-352, 134-146, 2012.

Rolf, T., Coltice, N., and Tackley, P. J.: Statistical cyclicity of the supercontinent cycle, Geophys. Res. Lett., 41, 2351-2358, 2014.

Şengör, A. M. C. and Burke, K.: Relative timing of rifting and volcanism on Earth and its tectonic implications, Geophys. Res. Lett., 5, 419-421, 1978.

Sobolev, S. V., Sobolev, A. V., Kuzmin, D. V., Krivolutskaya, N. A., Petrunin, A. G., Arndt, N. T., Radko, A., and Vasiliev, Y. R.: Linking mantle plumes, large igneous provinces and environmental catastrophes, Nature, 4777364, 312-316, 2011.

Stamps, D. S., Flesch, L. M., and Calais, E.: Lithospheric buoyancy forces in Africa from a thin sheet approach, Int. J. Earth Sci. (Geol. Rundsch.), 99, 1525, https://doi.org/10.1007/s00531-0100533-2, 2010.
Storey, B. C.: The role of mantle plumes in continental breakup: case histories from Gondwanaland, Nature, 377, 301-308, 1995.

Storey, M., Mahoney, J. J., Saunders, A. D., Duncan, R. A., Kelley, S. P., and Coffin, M. F.: Timing of hot spot-related volcanism and the breakup of Madagascar and India, Science, 267, 852855, 1995.

Sutton, J.: Long-term cycles in evolution of continents, Nature, 198, 731-735, 1963.

Tackley, P. J., Stevenson, D. J., Glatzmaier, G. A., and Schubert, G.: Effects of an endothermic phase change at $670 \mathrm{~km}$ depth in a spherical model of convection in the Earth's mantle, Nature, 361, 699-704, 1993.

Turcotte, D. L. and Emerman, S. H.: Mechanisms of active and passive rifting, Tectonophysics, 94, 39-50, 1983.

Van Heck, H. J. and Tackley, P. J., Planforms of self-consistently generated plates in 3D spherical geometry, Geophys. Res. Lett., 35, L19312, https://doi.org/10.1029/2008GL03519, 2008.

Weeraratne, D. and Manga, M.: Transitions in the style of mantle convection at high Rayleigh numbers, Earth Planet. Sc. Lett., 160, 563-568, 1998.

White, R. and McKenzie, D. P.: Magmatism at rift zones: the generation of volcanic continental margins and flood basalts, J. Geophys. Res., 94, 7685-7729, 1989

Wilson, J. T.: Did the Atlantic close and then re-open?, Nature, 211, 676-681, 1966.

Wolstencroft, M.: Understanding the thermal evolution of Earth, Ph.D. diss., Cardiff University, Cardiff UK, 2008.

Wolstencroft, M. and Davies, J. H.: Influence of the RingwooditePerovskite transition on mantle convection in spherical geometry as a function of Clapeyron slope and Rayleigh number, Solid Earth, 2, 315-326, 2011.

Yanagisawa, T., Yamagishi, Y., Hamano, Y., and Stegman, D. R.: Mechanism for generating stagnant slabs in 3-D spherical mantle convection models at Earth-like conditions, Phys. Earth Planet. In., 183, 342-352, 2010.

Ye, Y., Gu, C., Shim, S. H., Meng, Y., and Prakapenka, V.: The postspinel boundary in pyrolitic compositions determined in the laser-heated diamond anvil cell, Geophys. Res. Lett., 4111, 3833-3841, 2014.

Zhong, S., Zhang, N., Li, Z. X., and Roberts, J. H.: Supercontinent cycles, true polar wander, and very long-wavelength mantle convection, Earth Planet. Sc. Lett., 261, 551-564, 2007.

Yoshida, M.: Mantle convection with longest wavelength thermal heterogeneity in a 3D spherical model: degree one or two?, Geophys. Res. Lett., 35, L23302, https://doi.org/10.1029/2008GL036059, 2008.

Yoshida, M. and Santosh, M.: Mantle convection modeling of the supercontinent cycle: introversion, extroversion, or a combination?, Geosci. Front., 5, 77-81, 2014.

Ziegler, P. A. and Cloetingh, S.: Dynamic processes controlling evolution of rifted basins, Earth-Sci. Rev., 64, 1-50, 2004. 